\title{
Violência por Parceiro Íntimo: Características dos Envolvidos e da Agressão
}

\author{
Violencia por Compañero Íntimo: Características de los Involucrados y de la Agresión \\ Intimate Partner Violence: Characteristics of those Involved and Aggression
}

\author{
Maria do Socorro Barros Moraes \\ ORCID: http://orcid.org/0000-0002-3677-8506 \\ Universidade Federal do Pará - Pará/Brasil \\ Lília Ieda Chaves Cavalcante \\ ORCID: http://orcid.org/0000-0003-3154-0651 \\ Universidade Federal do Pará - Pará/Brasil \\ Zenildo Costa Pantoja \\ ORCID: http://orcid.org/0000-0002-7854-7685 \\ Universidade Federal do Pará - Pará/Brasil \\ Lucilene Paiva Costa \\ ORCID: http://orcid.org/0000-0002-1640-0530 \\ Universidade Federal do Pará - Pará/Brasil
}

\section{Resumo}

A violência contra mulher alcança índices alarmantes no Brasil. Entre seus eventos está aquela praticada no contex to da relação íntima de afeto ou em função desta. Este artigo apresenta os resultados obtidos na pesquisa científica intitulada "Homens Autores de Violência Conjugal: caracterização Biopsicossocial, Tipos de Agressão Praticada e suas Consequências Processuais" cujo objetivo foi descrever aspectos relativos à violência conjugal perpetrada pelo homem contra a mulher, a partir das relações existentes entre as características biopsicossociais do autor e da vítima, do tipo de ato violento desferido e as possíveis variações nas consequências processuais de tal ação. As informações foram coletadas em 150 processos de ação penal, sentenciados no ano de 2015 numa Vara Especializada em Violência Doméstica e Familiar da Comarca de Belém. Os dados submetidos ao método estatístico de análise de Cluster apresentaram a segmentação da amostra em três Clusters, segundo suas semelhanças e diferenças nas características individuais identificadas. A análise dos dados através da metodologia de Regressão Logística apontou que o rompimento da relação afetiva aumenta em 8,568 a razão de chance do homem vir a se tornar um praticante de violência física contra a ex-parceira.

Palavras-chave: Desenvolvimento; Violência conjugal; Violência por parceiro íntimo; Agressão contra a mulher.

\section{Resumen}

La violencia contra la mujer alcanza índices alarmantes en Brasil. Entre sus eventos está aquella practicada en el contexto de la relación íntima de afecto o en función de ésta. Este artículo presenta los resultados obtenidos en la investigación científica titulada "Hombres Autores de Violencia Conjugal: caracterización Biopsicosocial, Tipos de Agresión Practicada y sus Consecuencias Procesales" cuyo objetivo fue describir aspectos relativos a la violencia conyugal perpetrada por el hombre contra la mujer, a partir de las relaciones existentes entre las características biopsicosociales del autor y de la víctima, del tipo de acto violento desferido y las posibles variaciones en las consecuencias procesales 
de tal acción. La información fue recolectada en 150 procesos de acción penal, sentenciados en el año 2015 en una Vara Especializada en Violencia Doméstica y Familiar de la Comarca de Belém. Los datos sometidos al método estadístico de análisis de Cluster presentaron la segmentación de la muestra en tres Clusters, similitudes y diferencias en las características individuales identificadas. El análisis de los datos a través de la metodología de Regresión Logística apuntó que el rompimiento de la relación afectiva aumenta en 8,568 la razón de oportunidad del hombre de convertirse en un practicante de violencia física contra la ex pareja.

Palabras clave: Desarrollo; Violencia conyugal; Violencia por socio íntimo; Agresión contra la mujer.

\begin{abstract}
Violence against women reaches alarming levels in Brazil. Among its events is that practiced in the context of the intimate relation of affection or in function of this. This article presents the results obtained in the scientific research entitled "Men Authors of Conjugal Violence: Biopsychosocial Characterization, Types of Practiced Aggression and its Procedural Consequences", whose objective was to describe aspects related to the conjugal violence perpetrated by man against the woman, based on existing relationships between the biopsychosocial characteristics of the author and the victim, the type of violent act and the possible variations in the procedural consequences of such action. The data were collected in 150 criminal proceedings, sentenced in 2015 in a Specialized Chamber on Domestic and Family Violence in the Belem Region. Data submitted to the statistical method of Cluster analysis showed the segmentation of the sample in three clusters according to their similarities and differences in the identified individual characteristics. The analysis of the data through the Logistic Regression methodology showed that the breakdown of the affective relationship increases in 8,568 the ratio of chance of the man to become a practitioner of physical violence against the former partner.
\end{abstract}

Keywords: Development; Conjugal violence; Intimate partner violence; Aggression against women.

\section{Introdução}

Eventos de violência estão presentes nas diversas culturas, em todas as classes sociais, expressando-se de várias formas e em diferentes circunstâncias, o que fez com que fossem reconhecidos como um dos mais comuns problemas de saúde pública na atualidade (Ministério da Saúde, 2001). Para conceituação deste fenômeno é necessário considerar as características pessoais dos envolvidos, o contexto no qual a violência ocorre, as variações culturais, a forma como ela é percebida, os modelos relacionais subjacentes, e os instrumentos de prevenção e punição a ela direcionados (Almeida \& Lourenço, 2012; Gracia, 2014; Romagnoli, 2015).

Uma das definições de violência que comumente tem sido discutida e divulgada vem da World Health Organization (WHO), que relaciona este fenômeno à presença de uma ação proposital direcionada a uma pessoa, grupo ou até ao próprio emissor, visando causar prejuízos que podem alcançar diversas esferas, tais como a física, psicológica, social e moral. Entre os meios de ação mais observados estão a força física, armas, ameaças, aprisionamento e outros canais propiciadores da agressão. Os resultados vão desde a desestabilização da vítima, lesão corporal até a morte da mesma.

Referindo-se especificamente à violência intrafamiliar perpetrada contra a mulher, a Organização das Nações Unidas $(\mathrm{ONU})$ a define como qualquer ato agressivo a ela, que tenha como base sua condição de gênero, podendo causar-lhe danos em qualquer campo de sua existência, sendo desferida por meio de diferentes tipos de práticas, desde aquelas que machucam o corpo ou que afetam a sexualidade, passando pelo campo psicológico e social, entre outros, com sua 
efetivação em espaços públicos ou privados (WHO, 2015). Neste campo, a pessoa com a qual a vítima se relaciona ou se relacionou intimamente, marido, namorado ou amante, tendo sido apontado como algoz principal da mulher (Marasca, Colossi, \& Falcke, 2013; Silva, Coelho, \& Njaine, 2014).

Considerando que a violência contra a mulher tem entre seus pilares as diferenças de gênero, Santos e Vieira (2015) indicam que na conceituação dessa categoria são considerados os papéis sociais estabelecidos historicamente para o homem e a mulher, as semelhanças e os desníveis entre os mesmos. Coadunando com a mesma linha conceitual, Costa (2014) afirma que o homem, por um legado do patriarcalismo na construção de seu papel social, vê-se como superior em relação à mulher, tendo por ela um sentimento de propriedade, que visa sua dominação e contribui para que o mesmo perceba como legitima a disposição para corrigi-la agressivamente.

O delineamento histórico da posição socialmente estabelecida de submissão da mulher em relação ao homem tem embasado as ações dos institutos que se voltam à garantia de direitos, em especial da vítima, buscando efetivar medidas para inibir ações violentas. Ressalta-se que no contexto da violência conjugal o homem pode também estar na posição de vítima, porém, não será amparado pelo mesmo ordenamento jurídico (Colossi, Razera, Haack, \& Falcke, 2015; Costa, 2014).

Nesse contexto surgiu a Lei 11.340/2006, conhecida como Lei Maria da Penha, que estabelece diretrizes para coibir a agressão contra mulheres no espaço doméstico e familiar. Em seu artigo $5^{\circ}$, tal disposto legal diferencia três ambientes de ocorrência da violência, quais sejam: doméstico, familiar e Relação Íntima de Afeto (RIA). O ato agressivo pode se dar na constância de um relacionamento amoroso ou em consequência dele, perpetrada por pessoa com a qual a mulher tem ou teve envolvimento. O Mapa da Violência de 2015, aponta que o parceiro ou exparceiro (cônjuge, ex-cônjuge, namorado, exnamorado) é o principal agente agressor, acometendo vítimas desde as adolescentes até as idosas, com uma taxa de $42,28 \%$ (Colossi et al., 2015; Costa, 2014; Waiselfisz, 2015).

Ainda sobre o tema, a Lei Maria da Penha também descreveu cinco tipos de violência praticados contra a mulher: física, psicológica, sexual, moral e patrimonial. Conceitualmente tal dispositivo definiu a Violência Física como ações praticadas com a intenção de afetar a integridade ou a saúde corporal da vítima, assim como atitudes que levem a ofendida a desenvolver doenças físicas ou mentais, podendo ser desferida por meio de força física e/ou de armas ou outros meios lesivos. Este tipo de agressão deixa suas marcas além do corpo, pois a ela se associam medos, frustrações, decepções, ressentimentos, humilhação, vergonha, mesmo que não haja vestígio visível ou testemunha de sua ocorrência, assim, ela atinge também a psique de suas vítimas (Dourado \& Noronha, 2015; Santini \& Willians, 2016).

A Violência Psicológica atinge a subjetividade da vítima, é silenciosa, não deixa marcas visíveis, é extremamente danosa para quem é acometida por ela e pouco percebida pelos que estão em seu entorno, o que leva a continuidade de eventos por longo tempo. Se expressa através de ameaças, que podem ser inclusive de morte, chantagens, depreciação da parceira, intimidação, coação, aprisionamento, ridicularização, admoestação, entre outras, e muitas vezes se apresenta disfarçada, confundida com ciúme e zelo (Porto \& BucherMaluschke, 2014). Através de suas ações o agressor, consegue desestabilizar a vítima, a qual poderá apresentar diminuição de sua autoestima, perturbação mental, depressão, e outras doenças de fundo emocional (Silva et al., 2015). Em muitos casos esta é o ponto de partida para os demais tipos de agressões (Acosta, Gomes, Fonseca \& Gomes, 2015; Santini \& Willians, 2016).

Já a Violência Sexual, é perpetrada pelo agressor no ato sexual não consentido, em práticas sexuais indesejadas, em forçar a prostituição da parceira, em impedir ou obrigar uma gravidez, no voyeurismo, no casamento 
por conveniência do violador, além de outras modalidades de satisfação sexual do autor, em detrimento da vontade da vítima. Geralmente este tipo de agressão está associado à violência física e/ou psicológica, com uso da coerção, chantagem e outros meios que impedem a livre escolha da vítima, e em geral lhe causam sentimentos negativos como medo, culpa, nojo e vergonha, o que muitas vezes as impedem de procurar ajuda e/ou registrar a ocorrência junto aos órgãos especializados.

Quanto à Violência Patrimonial, consiste em atos agressivos que se materializam através dos bens da vítima, seja por retenção, subtração ou ainda a destruição integral ou parcial destes. Os objetos violados podem ser documentos, valores, material de trabalho ou qualquer outro recurso pertencente à vítima. A intenção do agressor pode estar ligada a manutenção da agredida sob o seu julgo, vinculado a um sentimento de posse, por vingança ou para obtenção de vantagens pessoais ao mesmo.

A Violência Moral corresponde aos crimes de calúnia, difamação ou injúria, através dos quais o ofensor macula a honra, objetiva ou subjetiva, da ofendida. Nesta modalidade o agressor pode atribuir de forma mentirosa o cometimento de ato criminoso à vítima, publicar situações, falsas ou reais, que desabonem sua visibilidade social e afete sua honra objetiva ou, colocá-la em situação vexatória por ato ou atribuição de qualidades pejorativas e/ou de cunho preconceituoso (Lei $n^{o}$ 11.340, 2006; Santos, 2014).

Deste modo, busca-se compreender este fenômeno através de estudos científicos que se dedicam a caracterizar seus partícipes, a partir de categorias sociodemográficas como: idade ou faixa etária; cor/etnia; estado civil; religião; escolaridade; situação de trabalho e renda entre outros (Stuart et al., 2013). Outros pesquisadores o fazem envolvendo atributos pessoais e aspectos do histórico de vida dos partícipes, dados biopsicológicos presentes em sua trajetória de vida, entre eles uso de drogas lícitas e/ou ilícitas; agressividade; dificuldade em lidar com a frustração; ciúme exacerbado; baixo autoestima; dependência afetiva; dependência financeira e ser oriundo de contexto familiar violento (Oliveira \& Bressan, 2014).

Nesta busca conceitual dos percursos da violência na relação de afeto, aspectos que caracterizam sua ocorrência também têm sido considerados, seja a presença de filhos, dependência financeira e ou afetiva, perdão, crença na mudança do outro, separação, condição de moradia, entre outros (Lopes, Fonsêca, Medeiros, Almeida \& Gouveia, 2016). Associam-se a estas categorias as características do ato violento, tipo, local de ocorrência, dia da semana, turno, eventos anteriores e seus registros (Paixão et al. 2014; Portella \& Ratton, 2015; Romagnoli, Abreu \& Silveira, 2013).

Nos relacionamentos amorosos, casamento ou fora dele, a violência transforma o espaço de encontro entre duas pessoas, com suas características pessoais e história pregressa, com seus aspectos positivos e negativos, com a intenção de compartilhar sentimento, de buscar satisfação mútua e individual, em um cenário conflituoso, que pode ou não levar ao fim da relação (Borges, Magalhães \& Féres-Carneiro, 2014). Ocorre que, tais ações violentas nem sempre são percebidas como tal pelos autores e por vezes, nem mesmo pela ofendida, só se externalizando e chegando ao conhecimento das instituições responsáveis pelos cuidados com a vítima e repreensão ao agressor, quando se tornam excessivas, lesivas à saúde física e/ou mental da mulher (Silva et al., 2015).

Tal fenômeno carece de suporte no acolhimento de suas vítimas e agressores, além da família. Assim, diversos seguimentos profissionais são requisitados, tais como psicólogos, médicos, assistentes sociais, enfermeiros, entre outros. Especificamente no campo da psicologia várias especialidades estão ligadas ao atendimento dos envolvidos neste tipo de violência, destacando o psicólogo clínico, no acompanhamento individualizado ou grupal às vítimas e ofensores em espaços particulares ou em programas 
institucionalizados do poder público, na de rede atendimento psicossocial, voltados à essa demanda; o psicólogo hospitalar, visto que os hospitais são espaços onde muitas vítimas buscam ajuda, e por vezes omitem os reais agentes que lhe causaram lesões e traumatismos. O psicólogo forense ou jurídico, no contexto judiciário, é o responsável pelo atendimento dos envolvidos, vítimas e agressores, no sentido de averiguar o entrelaçamento entre o comportamento humano e as leis, oferecendo subsídios técnicos aos juízes responsáveis pela aplicação do ordenamento jurídico (Rosa \& Freitas, 2017; Rolim \& Falcke, 2017).

Importante referir que os esforços empreendidos pelos estudiosos da área têm contribuído com o saber sobre a violência por parceiro íntimo, porém, por sua alta complexidade, muito há ainda que se investir na ampliação do debate sobre o tema, por meio de pesquisas que busquem aprofundar $o$ conhecimento acerca dos elementos que compõem este fenômeno. O objetivo deve ser obter subsídios que favoreçam a formatação de estratégias diferenciadas no combate à violência, que focalizem o problema, seus partícipes, além da família, da comunidade e das entidades públicas e privadas responsáveis pelo atendimento aos mesmos (Acosta et al., 2015; Razera, Cenci \& Falcke, 2014).

\section{Método}

Trata-se de um estudo documental, com abordagem quantitativa e uso de fontes secundárias, que foi realizado com a aquiescência da autoridade judiciária, Tribunal de Justiça do Estado do Pará-TJPA, e atenção aos princípios éticos previstos na Resolução 510/2016 do Conselho Nacional de Saúde (CNS), em particular o que diz respeito à confidencialidade, que é a garantia do resguardo das informações dadas em confiança e a proteção contra a sua revelação não autorizada. O acesso aos dados ocorreu por meio de consulta em documentos impressos e arquivo de mídia, que compõe os processos transitado em julgado no ano de 2015 em uma Vara Especializada em violência Doméstica e
Familiar contra a Mulher, da comarca de Belém do Pará.

Para coleta dos dados utilizou-se um Formulário de Caracterização Biopsicossocial do Autor e da Vítima de Violência Conjugal (FCBAVVC), desenhado com o objetivo de buscar nos documentos processuais informações que retratassem as características que definem o perfil dos autores e vítimas de violência na relação íntima, o tipo de violência praticada e as consequências processuais sofridas pelo agressor. Para conhecer o quantitativo de processos de ação penal sentenciados no ano de 2015, foi solicitada à Vara a relação destes, onde foi apresentado um total de 488 processos.

Os processos judiciais disponibilizados para consulta estavam dispostos em caixas, de acordo com a organização funcional do local, que insere no mesmo espaço processos de ação penal referente a violência contra mulher praticada por qualquer agente e de Medidas Protetivas. Assim, foi necessário triar os processos aderentes aos critérios de inclusão: 1) Ter sido sentenciado no ano de 2015; 2) Ser Processo de Ação Penal; 3) Envolver violência por parceiro íntimo em relações heterossexuais e 4) Ser homem o denunciado pela violência.

Posteriormente, deu-se início à coleta dos dados, com uma amostra de pesquisa composta por 150 processos jurídicos, o que equivale a 52,08\%, dos 288 autos de ação penal que se enquadraram aos critérios de inclusão e estavam disponíveis para consulta, no período de fevereiro a junho de 2016, na Secretaria da Vara ou no Arquivo Geral da instituição. As informações obtidas foram armazenadas inicialmente em planilha do programa EXCEL, e posteriormente organizadas por categorias, e transferidas para o Statistical Package for the Social Sciences (SPSS), criando assim um banco de dados com o material extraído dos documentos.

O banco de dados foi submetido e avaliado por meio de quatro tipos de análises estatísticas diferentes. Em um primeiro momento, foram utilizadas técnicas de análise 
estatística descritiva com o objetivo de mapear os participantes de acordo com as variáveis pesquisadas. Para tanto, utilizou-se o Teste de igualdade de duas Proporções, pois o mesmo possibilitou verificar se havia significância estatística na proporção de respostas entre duas variáveis, tendo sido trabalhadas as seguintes hipóteses:

$$
\left\{\begin{array}{l}
H_{0}: \mathrm{p}_{1}=p_{2} \\
H_{1}: \mathrm{p}_{1} \neq p_{2}
\end{array}\right.
$$

Para realização do teste inicialmente foi utilizado o cálculo:

$$
f_{1}=\frac{x_{1}}{n_{1}}, f_{2}=\frac{x_{2}}{n_{2}} \text { e } \hat{p}=\frac{x_{1}+x_{2}}{n_{1}+n_{2}}
$$

A estatística teste foi calculada utilizando a fórmula:

$$
Z_{c a l}=\frac{f_{1}-f_{2}}{\sqrt{\hat{p}(1-\hat{p})\left(\frac{1}{n_{1}}+\frac{1}{n_{2}}\right)}}
$$

Neste ponto, o nível de significância (probabilidade de erro) definido para este trabalho foi de $0,05(5 \%)$, tendo os intervalos de confiança estatísticos sido considerados em $95 \%$.

Para identificar as características que compõem o perfil sociodemográfico (1) e biopsicológico (2) dos homens e mulheres envolvidos em situação de violência na intimidade, assim como da relação afetiva (3) e do ato violento (4), utilizou-se o método estatístico de análise descritiva, através do pacote do SPSS. Foram analisadas as seguintes categorias: (1) faixa etária, estado civil, cor/etnia, religião, grau de escolaridade, situação de trabalho, profissão/ocupação, renda, condição e bairro de moradia; (2) uso de álcool, uso de drogas ilícitas, condição de saúde, agressividade, dificuldade em lidar com a frustração, humor irritável, ciúme e dependência afetiva; (3) filhos, tempo de relação, situação da relação no ato da agressão e após, tempo de separação, vínculo afetivo do autor com a vítima, residência de ambos antes e depois da violência, a ocorrência de agressões anteriores e seus respectivos registros; (4) tipo de agressão, local de ocorrência, turno e o dia semana.

Sobre os elementos processuais pertinentes a este tipo de crime, foram pesquisadas categorias tais como, o ano em que foi praticado, a confissão do crime por parte do denunciado, apresentação de defesa relativa à acusação que lhe estava sendo imposta, comparecimento às audiências marcadas, justificativa de ausências, sentença prolatada pelo juiz, penalização recebida e dosimetria da pena. Tais variáveis buscam demonstrar o rito processual de responsabilização do denunciado, desde a denúncia até a sentença.

O banco de dados foi submetido à análise de grupos ou de Cluster, que é uma técnica exploratória de análise multivariada que permite agrupar indivíduos ou variáveis em grupos homogêneos ou compactos, relativamente a uma ou mais características comuns. Objetivou-se assim, identificar a possível subdivisão dos autores de agressão, segundo as características de seu perfil, correlacionando-as com as características da vítima, da relação, do ato praticado e das consequências processuais sofridas.

Também buscou-se demonstrar qual a razão de chance de um homem vir a se tornar um agressor da parceira íntima, a partir da análise dos dados coletados. Para tanto, utilizou-se o modelo de Regressão Logística, que por sua funcionalidade, na comparação entre variáveis, possibilita esse tipo de predição. Para submissão ao modelo, os dados foram reagrupados e transformados em categorias binárias. Inicialmente, realizou-se uma análise das variáveis relacionadas com as características do autor de agressão física, assim como, aquelas que descrevem a agressão e a vítima. Considerou-se como variável dependente "Praticou Agressão Física" (com uso de força e/ou arma), em função desta ser a modalidade que é mais facilmente reconhecida como ato violento no contexto social (Gomes, Silveira, Diniz, Paixão, Camargo \& Gomes, 2013). 
O modelo de Regressão Logística múltipla foi estimado utilizando um procedimento iterativo de inclusão de variáveis chamado Stepwise Forward não automático. Utilizou-se o teste da razão de verossimilhança e o critério de Akaike (AIC) para avaliar a entrada das variáveis. Foram apresentadas as razões de chance (OR) e os respectivos intervalos de confiança de $95 \%$. Em todas as análises foi adotado um nível de significância de $5 \%$.

Visando a adequação do modelo, foram feitas as estatísticas de Bondade de Ajuste de Pearson, Hosmer-Lemeshow e Deviance que verificam as hipóteses $\mathrm{H}_{0}$ : o ajuste dos dados é bom versus $\mathrm{H}_{1}$ : o ajuste dos dados não é bom, para o estudo da chance de alguma pessoa ser autor de agressão física no contexto íntimo de afeto. Após ajustado o modelo foi utilizado para estimar a probabilidade alguma pessoa de vir a ser autor de agressão física.

$$
P(y)=\frac{1}{1+e^{-\left(0.77 X_{1}-1.13 X_{2}+2.14 X_{3}\right)}}+e_{1}
$$

\section{Resultados}

A análise descritiva dos dados permitiu identificar as principais características biopsicossociais do autor e da vítima, assim como as características da agressão e da relação afetiva. Os resultados obtidos no aspecto sociodemográfico, apontaram que os homens em sua maioria estão na faixa etária entre os 24 e $34 \operatorname{anos}(45,3 \%)$, são solteiros $(54,7 \%)$, de cor/etnia parda (37,3\%), católicos (26\%), ensino fundamental $(42,6 \%)$. Já as mulheres, são da mesma faixa etária $(42,7 \%)$, solteiras $(61,3 \%)$, pardas $(32,7 \%)$, evangélicas $(3,3 \%)$, ensino médio (34\%), como demonstrado na tabela 1. Ainda sobre os homens, os dados demonstraram que $56,7 \%$ desempenhavam atividade remunerada, com faixa salarial de até dois salários mínimos (26\%) e residiam com parentes (20\%). As mulheres, em sua maioria, não exerciam atividade remunerada $(38,2 \%)$, porém, moravam em casa própria $(22,7 \%)$.
Tabela 1

Características do autor e da vítima de violência na relação afetiva

\begin{tabular}{|c|c|c|c|c|}
\hline \multirow{2}{*}{ Categorias } & \multicolumn{2}{|c|}{ Autor } & \multicolumn{2}{|c|}{ Vítima } \\
\hline & $F$ & $\%$ & $F$ & $\%$ \\
\hline \multicolumn{5}{|l|}{ Faixa Etária } \\
\hline De 18 a 23 & 13 & 8,7 & 32 & 21,3 \\
\hline De 24 a 34 & 68 & 45,3 & 64 & 42,7 \\
\hline De 35 a 45 & 39 & 26 & 35 & 23,3 \\
\hline De 46 a 56 & 22 & 14,7 & 7 & 4,7 \\
\hline Acima de 57 & 5 & 3,3 & 3 & 2 \\
\hline Sem & 3 & 2 & 9 & 6 \\
\hline \multicolumn{5}{|l|}{ Informação } \\
\hline \multicolumn{5}{|l|}{ Estado Civil } \\
\hline Casado (a) & 19 & 12,7 & 9 & 6 \\
\hline Divorciado (a) & 6 & 4 & 3 & 2 \\
\hline Separado (a) & 2 & 1,3 & 7 & 4,7 \\
\hline Solteiro (a) & 82 & 54,7 & 92 & 61,3 \\
\hline União Estável & 34 & 22,7 & 28 & 18,7 \\
\hline Viúvo (a) & - & - & 2 & 1,3 \\
\hline Sem & 7 & 4,7 & 9 & 6 \\
\hline \multicolumn{5}{|l|}{ Informação } \\
\hline \multicolumn{5}{|l|}{ Cor/etnia } \\
\hline Branca & 5 & 3,3 & 1 & 0,7 \\
\hline Parda & 56 & 37,3 & 49 & 32,7 \\
\hline Preta & 5 & 3,3 & 1 & 0,7 \\
\hline Sem & 84 & 56 & 99 & 66 \\
\hline \multicolumn{5}{|l|}{ Informação } \\
\hline \multicolumn{5}{|l|}{ Religião } \\
\hline Católica & 39 & 26 & 1 & 0,7 \\
\hline Evangélica & 9 & 6 & 5 & 3,3 \\
\hline Candomblé & - & - & 1 & 0,7 \\
\hline Sem religião & 2 & 1,3 & - & - \\
\hline Sem & 100 & 66,7 & 143 & 95,3 \\
\hline \multicolumn{5}{|l|}{ Informação } \\
\hline \multicolumn{5}{|l|}{ Escolaridade } \\
\hline Nunca estudou & 3 & 2 & - & - \\
\hline $\begin{array}{l}\text { Fundamental } \\
\text { (incompleto e } \\
\text { completo) }\end{array}$ & 64 & 42,6 & 50 & 33,3 \\
\hline $\begin{array}{l}\text { Médio } \\
\text { (incompleto e } \\
\text { completo) }\end{array}$ & 50 & 33,3 & 51 & 34 \\
\hline $\begin{array}{l}\text { Superior } \\
\text { (incompleto e } \\
\text { completo }\end{array}$ & 16 & 10,6 & 18 & 6,7 \\
\hline \multicolumn{5}{|l|}{ Informação } \\
\hline \multicolumn{5}{|c|}{$\begin{array}{l}\text { Nota. Fonte: Recuperado de Homens Autores de } \\
\text { Violência Conjugal: Caracterização Biopsicossocial e } \\
\text { a Relação com a Vítima, o Tipo de Agressão Praticada } \\
\text { e suas Consequências Processuais, de Moraes, M. S. } \\
\text { B., 2017. Dissertação de Mestrado, p.64. Programa de } \\
\text { Pós-Graduação em Teoria e Pesquisa do } \\
\text { Comportamento, Universidade Federal do Pará, } \\
\text { Belém. }\end{array}$} \\
\hline
\end{tabular}


Os resultados referentes às características biopsicológicas pesquisadas, considerando as categorias: uso de bebidas alcoólicas e drogas ilícitas, agressividade e dificuldade em lidar com a frustração, estão descritos na tabela 2. Pelos dados obtidos, é possível identificar que a maioria dos agressores faz uso de bebida alcoólica $(51,3 \%)$ e $12 \%$ de drogas ilícitas. Com relação à vítima, nos processos em que havia esta informação sobre a mesma, observou-se que somente $6 \%$ ingeriam bebida alcoólica. Com relação às características comportamentais dos envolvidos, neste estudo verificou-se que $68 \%$ dos acusados apresentam comportamentos agressivos; dificuldade em lidar com a frustação $(26,7 \%)$.

Tabela 2

Dados das características biopsicológicas do autor e da vítima de violência na relação afetiva

\begin{tabular}{lcccc}
\hline \multirow{2}{*}{ Categorias } & \multicolumn{2}{c}{ Autor } & \multicolumn{2}{c}{ Vítima } \\
\cline { 2 - 5 } & $\boldsymbol{f}$ & $\boldsymbol{\%}$ & $\boldsymbol{F}$ & $\mathbf{\%}$ \\
\hline Usuário de Bebida & & & & \\
Alcoólica & & & & \\
Sim & 77 & 51,3 & 9 & 6 \\
Não & 30 & 20 & 19 & 12,7 \\
Sem Informação & 43 & 28,7 & 122 & 81,3 \\
\hline Usuário de Drogas & & & & \\
Ilícitas & & & & \\
Sim & 19 & 12,7 & - & - \\
Não & 32 & 21,3 & 24 & 16 \\
Sem Informação & 99 & 66 & 126 & 84 \\
\hline Agressividade & & & & \\
Sim & 102 & 68 & 16 & 10,7 \\
Não & 27 & 18 & 50 & 33,3 \\
Sem Informação & 21 & 14 & 84 & 56 \\
\hline Dificuldade em lidar & & \multicolumn{3}{c}{} \\
com a frustração & & & & \\
Sim & 40 & 26,7 & 2 & 1,3 \\
Não & 89 & 59,3 & 60 & 40 \\
Sem Informação & 21 & 14 & 88 & 58,7 \\
\hline Nota Fon
\end{tabular}

Nota. Fonte: Recuperado de Homens Autores de Violência Conjugal: Caracterização Biopsicossocial e a Relação com a Vítima, o Tipo de Agressão Praticada e suas Consequências Processuais, de Moraes, M. S. B., 2017. Dissertação de Mestrado, p.69. Programa de PósGraduação em Teoria e Pesquisa do Comportamento, Universidade Federal do Pará, Belém.

Do mesmo modo, verificou-se nos registros que $13,3 \%$ dos homens apresentavam humor irritável, ciúmes exacerbados em relação à vítima $(18 \%)$ e dependência afetiva por suas parceiras $(13,3 \%$.). Sobre as vítimas os dados revelaram menor índice de agressividade $(10,7 \%)$ e ciúme exacerbado (7,3\%). No entanto, observou-se que as mulheres foram as que mais mostraram dependência afetiva do parceiro íntimo, com $16 \%$ de frequência.

Tabela 3

Dados sobre as características da relação afetiva

\begin{tabular}{lcc}
\multicolumn{1}{c}{ Categorias } & $\boldsymbol{f}$ & $\mathbf{\%}$ \\
\hline Tempo da Relação & & \\
De 1 a 6 meses & 2 & 1,3 \\
De 7 a 12 meses & 7 & 4,7 \\
Entre 1 a 3 anos & 26 & 17,3 \\
Entre 4 a 7 anos & 43 & 28,7 \\
Entre 8 a 10 anos & 23 & 15,3 \\
Entre 11 a 20 anos & 29 & 19,3 \\
Acima de 20 anos & 14 & 9,3 \\
SI & 6 & 4 \\
\hline
\end{tabular}

\begin{tabular}{lcc}
\hline Situação da Relação na Ocasião da & & \\
Agressão & & \\
Relacionamento ativo & 56 & 37,3 \\
Relacionamento rompido & 89 & 59,3 \\
SI & 5 & 3,3 \\
\hline Vínculo Afetivo $^{\prime}$ & \\
Parceiro atual $^{1}$ & 64 & 42,7 \\
Ex-parceiro $^{2}$ & 85 & 56,7 \\
SI & 1 & 0,7 \\
\hline Ocorrência de violência anterior & & \\
Sim & 98 & 65,3 \\
Não & 8 & 5,3 \\
SI & 44 & 29,3 \\
\hline
\end{tabular}

Registros de agressões anteriores

$\begin{array}{lll}\text { Sim } & 46 & 30,7\end{array}$

$\begin{array}{lll}\text { Não } & 48 & 32,0\end{array}$

SI $\quad 56 \quad 37,3$

Nota. Fonte: Recuperado de Homens Autores de Violência Conjugal: Caracterização Biopsicossocial e a Relação com a Vítima, o Tipo de Agressão Praticada e suas Consequências Processuais, de Moraes, M. S. B., 2017. Dissertação de Mestrado, p.70. Programa de Pós-Graduação em Teoria e Pesquisa do Comportamento, Universidade Federal do Pará, Belém.

1 esposo, convivente, companheiro, namorado.

2 ex-esposo, ex-convivente, ex-companheiro, exnamorado.

Nos resultados demonstrados na tabela 3, estão os dados coletados referentes à caracterização da relação afetiva entre os parceiros íntimos, sendo possível visualizar que a maioria apresentava relação com tempo entre 04 e 07 anos (28,7\%), estando 59,3\% destas rompida no momento da agressão denunciada. $\mathrm{O}$ ex-parceiro da vítima é indicado como autor 
da agressão em $56,7 \%$ dos casos, porém, é expressiva a denúncia dessa prática por atuais companheiros $(42,7 \%)$. Há relatos de ocorrência de atos de violência anterior a atual $(65,3 \%)$, dos quais $32 \%$ não foram denunciados aos órgãos de proteção, sendo $51 \%$ destas de agressão física. As informações coletadas apontam ainda, que $73 \%$ dos envolvidos tinham filhos, a separação estava num período entre 1 e 6 meses $(24,4 \%)$ e moravam em casas separadas $(51,3 \%)$.

Ao focalizar as características da agressão, os resultados, apresentados na figura 1, evidenciaram haver uma equivalência entre a agressão física e a psicológica (68\%), destaque para agressão física com uso de força $(60,7 \%)$. Cabe ressaltar que algumas mulheres sofreram mais de um tipo de violência (68\%). No tocante ao local de ocorrência, a maioria dos casos aconteceu na residência do casal (32\%), em finais de semana (54\%), no turno da noite $(36,7 \%)$, praticada por homens que haviam consumido bebida alcoólica (34\%).

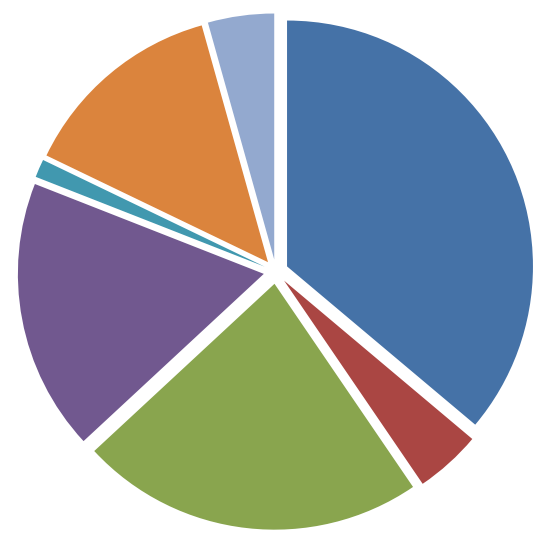

- Agressão fisica com uso de força $(60,7 \%)$

- Agressão fisica com uso de armas (7,3\%)

- Agressão Psicológica com ameça de morte (38\%)

- Agressão Psicológica sem ameça de morte (30\%)

- Agressão sexual (2\%)

- Agressão moral (22,7\%)

- Agressão patrimonial (7,3\%)

Figura 1. Distribuição da violência de acordo com o tipo de agressão praticada

Fonte: Recuperado de Homens Autores de Violência Conjugal: Caracterização Biopsicossocial e a Relação com a Vítima, o Tipo de Agressão Praticada e suas Consequências Processuais, de Moraes, M. S. B., 2017. Dissertação de Mestrado, p.71. Programa de Pós-
Graduação em Teoria e Pesquisa do Comportamento, Universidade Federal do Pará, Belém.

Sobre os percursos procedimentais nos órgãos de atendimento aos envolvidos em situação de violência na relação de afeto, em especial na oitiva dos denunciados, as informações denotam que, nos inquéritos policiais, nas delegacias especializadas, $62,7 \%$ dos inqueridos negaram tal prática, passando este escore para $21,7 \%$, de negação nas audiências judiciais. No rito processual, não apresentaram defesa formal à acusação $(46,7 \%)$, nem compareceram às audiências marcadas (36,7\%). Quanto à responsabilização do acusado, 42,7\% dos denunciados foram considerados culpados e receberam sentença condenatória em torno de 1 a 2 meses $(17,3 \%)$.

Buscando fazer o agrupamento de indivíduos, de acordo com suas semelhanças no que concerne as características biopsicossociais, o banco de dados foi submetido ao método de Análise de Cluster e resultou na distinção de três grandes grupos de homens denunciados por agressão, com características similares, estando 99 no Cluster 1 (C1), 21 no Cluster 2 (C2) e 30 no Cluster 3 (C3). O modelo Two Step utilizado, apontou uma qualidade dos Clusters entre 0,20 a 0,50, significando uma solução justa entre eles, com aceitação confiável de seus resultados.

Levando em consideração as principais variáveis de cada Cluster, pode-se dizer que no $\mathrm{C} 1$, segundo suas características sociodemográficas, estão denunciados por agressão na relação afetiva que estão na faixa entre 18 e acima dos 57 anos (97), de cor parda (41), ensino fundamental incompleto (44) e moram em casa própria (20). Considerando as características biopsicológicas, são usuários de álcool (60), com comportamento agressivo (80) e percebem a violência como solução de conflitos (34). Os representantes desse grupo, já estavam separados das vítimas (54), tendo tal rompimento ocorrido entre 1 a 6 meses (23). No tocante ao ato violento e aos reflexos processuais, cometeram em maior número agressão física com uso de força (62) e de arma (10), tendo como local de ocorrência a casa do 
casal (36), especialmente no sábado (20) e no domingo (20). Tais indivíduos já tinham praticado agressão anterior (71), na modalidade física (54) e respondiam a processos anteriores (38). Em função de seus atos foram presos (33), e durante $o$ curso do processo não compareceram às audiências (39) e não justificaram a ausência (15), sendo condenados pela prática da agressão (43).

No Cluster 2, estão os denunciados por agressão que apresentam perfil socioeconômico com as seguintes características: faixa etária semelhante aos integrantes do Cluster 3, 24 a 34 anos. Como condição de moradia, a maioria dos participantes deste grupo residia com parentes (5). No que se refere à escolaridade parte dos membros chegou até o ensino fundamental incompleto (5) e a outra parte concluiu o ensino médio (5). Os homens desse grupo também já haviam se separado de suas parceiras há um tempo de entre 7 a 12 meses. Como características biopsicológicas usuários de álcool (4), sem registro de agressividade ou antecedentes criminais. Entre os aspectos da violência e processuais, neste grupo encontramos indivíduos que cometeram agressão física, porém somente com uso de força (13), em locais públicos (6), no turno da noite (9), especialmente na sexta-feira (5) e no domingo (5). Estes participantes em geral compareceram a todas as audiências e foram absolvidos das acusações que lhes foram imputadas (11).

O Cluster 3, congrega o menor número de participantes, os quais apresentam como características sociodemográficas, ter idade entre 24 a 34 anos, sem nenhum representante com idade acima de 57 anos. A baixa escolaridade é prevalente, situada no ensino fundamental incompleto (9). Estes participantes em sua maioria residem com parentes (8). Entre as características biopsicológicas estão: o consumo de bebida alcoólica (13) e agressividade (22). A relação amorosa já estava rompida entre 1 e 6 meses. Sobre a violência e os dados processuais, neste grupo estão participantes que de modo equiparado cometeram agressão física com uso de força (16) e agressão psicológica (15). Os atos foram praticados na residência do casal (9) ou da vítima (9). Os dias da semana onde mais ocorreram as agressões foram as sextas-feiras, domingos e segundas-feiras, desferidas em horário noturno. Os autores já haviam praticado violência anterior (20), em especial na modalidade física (14). Os indivíduos não respondiam a processos judiciais anteriores (13) e compareceram a todas as audiências (10). Em sua maioria foram julgados culpados pela agressão perpetrada (15).

Na tabela 4, verifica-se a confiabilidade e coerência com as quais os Clusters foram segmentados. Nesta etapa, foi utilizado o método de análise discriminante, para confirmar em que medida os participantes foram corretamente agrupados.

Os resultados demonstram que 100\% dos participantes do grupo original foram corretamente classificados e na validação cruzada este percentual passa a ser de $96 \%$. Considerando a função discriminante é possível afirmar que a classificação da amostra foi coerente, num coeficiente de $100 \%$, para os três grupos originais. Na variação cruzada do Grupo 1, dos 99 participantes, 93,9\% foram alocados corretamente, sendo 6,1 realocados no Grupo 3. Já os que compõem o Grupo 2 e o Grupo 3 foram $100 \%$ inseridos em seus respectivos grupos.

A partir da análise discriminante, foi possível gerar um Dendograma (Figura 2), composto pelos três Clusters, cada qual com seu centroide, ponto de concentração que atrai para si os participantes com as características mais próximas daqueles que ali se localizam, ou seja, quanto mais próximo do centro, mais afinidades o participante tem com aquele grupo, sendo que o inverso também é verdadeiro. No Dendograma temos o Grupo 1 representado pela cor azul, o Grupo 2 pela cor verde e o Grupo 3 com amarelo. 
Tabela 4

Resultado da análise discriminante do agrupamento de Clusters dos denunciados por agressão

\begin{tabular}{|c|c|c|c|c|c|c|}
\hline \multirow{2}{*}{\multicolumn{3}{|c|}{ Grupos de autores de agressão }} & \multicolumn{3}{|c|}{ Probabilidade de Pertencer ao Grupo } & \multirow{2}{*}{ Total } \\
\hline & & & G1 & G2 & G3 & \\
\hline \multirow{6}{*}{ Original } & & Cluster 1 & 99 & 0 & 0 & 99 \\
\hline & Grupos & Cluster 2 & 0 & 21 & 0 & 21 \\
\hline & & Cluster 3 & 0 & 0 & 30 & 30 \\
\hline & & Cluster 1 & 100,0 & 0,0 & 0,0 & 100 \\
\hline & $\%$ & Cluster 2 & 0,0 & 100,0 & 0,0 & 100 \\
\hline & & Cluster 3 & 0,0 & 0,0 & 100,0 & 100 \\
\hline \multirow{6}{*}{$\begin{array}{c}\text { Validação Cruzada } \\
\text { b }\end{array}$} & & Cluster 1 & 93 & 0 & 6 & 99 \\
\hline & Grupos & Cluster 2 & 0 & 21 & 0 & 21 \\
\hline & & Cluster 3 & 0 & 0 & 30 & 30 \\
\hline & & Cluster 1 & 93,9 & 0,0 & 6,1 & 100 \\
\hline & $\%$ & Cluster 2 & 0,0 & 100,0 & 0,0 & 100 \\
\hline & & Cluster 3 & 0,0 & 0,0 & 100,0 & 100 \\
\hline
\end{tabular}

a. $100,0 \%$ dos casos originais foram classificados corretamente.

b. $96,0 \%$ dos casos da validação cruzada foram corretamente classificadas.

Nota. Fonte: Recuperado de Homens Autores de Violência Conjugal: Caracterização Biopsicossocial e a Relação com a Vítima, o Tipo de Agressão Praticada e suas Consequências Processuais, de Moraes, M. S. B., 2017. Dissertação de Mestrado, p.79. Programa de Pós-Graduação em Teoria e Pesquisa do Comportamento, Universidade Federal do Pará, Belém.

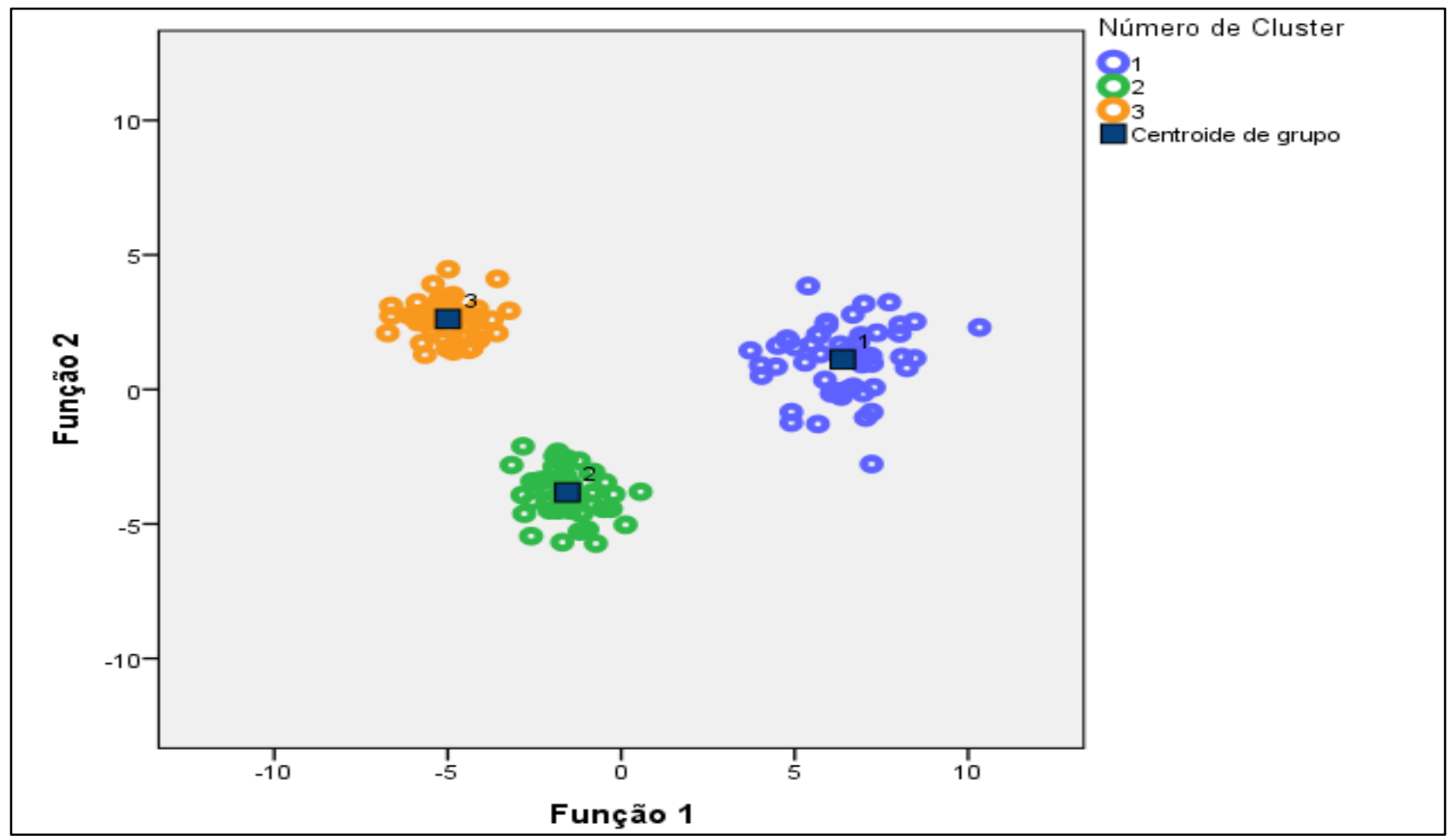

Figura 2. Dispersão dos denunciados por agressão da parceira íntima

Fonte: Recuperado de Homens Autores de Violência Conjugal: Caracterização Biopsicossocial e a Relação com a Vítima, o Tipo de Agressão Praticada e suas Consequências Processuais, de Moraes, M. S. B., 2017. Dissertação de Mestrado, p.80. Programa de Pós-Graduação em Teoria e Pesquisa do Comportamento, Universidade Federal do Pará, Belém.

A análise dos dados através do método de Regressão Logística revelou uma associação significativa entre a variável dependente "agressão física atual" e as variáveis: violência física anterior, violência psicológica anterior e Situação da Relação na ocasião da agressão rompida. Na tabela 5 está apresentado o modelo que melhor se ajustou a esse propósito. 
Tabela 5

Modelo de Regressão Logística para homens denunciados por violência contra a parceira íntima

\begin{tabular}{lcccc}
\hline Variáveis & Parâmetro & $\begin{array}{c}\text { Teste de } \\
\text { Wald }\end{array}$ & $\begin{array}{c}\text { P-Valor } \\
\text { Razão de } \\
\text { Chance }\end{array}$ \\
\hline Violência Física anterior &, 770 & 3,213 & $\mathbf{, 0 3 1}$ & $\mathbf{2 , 1 5 9}$ \\
Violência Psicológica anterior & $-1,133$ & 5,532 & $\mathbf{, 0 1 9}$ & $\mathbf{3 2 2}$ \\
Situação da Relação rompida na ocasião da agressão & 2,148 & 19,575 & $\mathbf{, 0 0 0}$ & $\mathbf{8 , 5 6 8}$ \\
Constante &,- 157 &, 323 & $\mathbf{, 5 7 0}$ & $\mathbf{, 8 5 5}$ \\
\hline
\end{tabular}

Nota. Fonte: Recuperado de Homens Autores de Violência Conjugal: Caracterização Biopsicossocial e a Relação com a Vítima, o Tipo de Agressão Praticada e suas Consequências Processuais, de Moraes, M. S. B., 2017. Dissertação de Mestrado, p.81. Programa de Pós-Graduação em Teoria e Pesquisa do Comportamento, Universidade Federal do Pará, Belém.

O modelo de Regressão Logística apresentou coeficiente positivo de 0,770 para variável violência física anterior e 2,148 para Situação da Relação rompida na ocasião da agressão. Tais resultados demonstram que há uma razão de chance de 2,159 , de um homem que cometeu agressão física anterior, vir a cometer tal violação novamente. As chances dessa prática se elevam para 8,568 , quando a relação é rompida. Quanto a variável "violência psicológica anterior" apresentou como resultado coeficiente negativo $(-0,133)$, e assim sugere que um homem que praticou agressão psicológica anterior tem menos chances de praticar agressão física, quando comparado a um que praticou agressão física anterior, numa razão de chance 0,322 .

A tabela 6 apresenta os resultados probabilísticos de um homem vir a ser autor de agressão física. Observa-se que a maior probabilidade dessa ocorrência se situa entre os autores que praticaram violência física anterior, que tiveram a relação conjugal rompida, mas não praticaram agressão psicológica anterior.

Tabela 6

Probabilidade de praticar violência física segundo algumas combinações das variáveis explicativas no modelo

\begin{tabular}{c|c|c|c}
\hline $\begin{array}{c}\text { Violência Física Anterior } \\
\left(\mathbf{X}_{\mathbf{1}}\right)\end{array}$ & $\begin{array}{c}\text { Violência Psicológica } \\
\text { Anterior } \\
\left(\mathbf{X}_{\mathbf{2}}\right)\end{array}$ & $\begin{array}{c}\text { Situação da Relação } \\
\text { na Ocorrência da } \\
\text { agressão atual }\left(\mathbf{X}_{\mathbf{3}}\right)\end{array}$ & Probabilidades $(\boldsymbol{\%})$ \\
\hline NÃO & NÂO & Relacionamento Ativo & 46.09 \\
NÃO & NÃO & Relacionamento Rompido & 87.99 \\
SIM & NÃO & Relacionamento Ativo & 64.85 \\
SIM & NÃO & Relacionamento Rompido & 94.05 \\
NÃO & SIM & Relacionamento Rompido & 21.58 \\
NÃO & SIM & Relacionamento Ativo & 70.22 \\
SIM & SIM & Relacionamento Rompido & 37.26 \\
SIM & SIM & 83.58 \\
\hline
\end{tabular}

Nota. Fonte: Recuperado de Homens Autores de Violência Conjugal: Caracterização Biopsicossocial e a Relação com a Vítima, o Tipo de Agressão Praticada e suas Consequências Processuais, de Moraes, M. S. B., 2017. Dissertação de Mestrado, p.82. Programa de Pós-Graduação em Teoria e Pesquisa do Comportamento, Universidade Federal do Pará, Belém.

\section{Discussão}

O estudo foi realizado de forma a produzir uma compreensão do fenômeno da violência conjugal, focalizando características biopsicossociais do autor, da vítima, da relação, da violência, dos percursos jurídicos e suas interconexões. No que refere a descrição das características sociodemográficas da população estudada, identificou-se similaridade com os resultados encontrados por autores que realizaram suas pesquisas em instituições públicas, localizando os autores de agressão como pertencentes a classe menos favorecida da sociedade, com pouca escolaridade, exercendo atividade remunerada, com baixa renda e moradia em bairros populares (Akhter \& Wilson, 2015; Dourado \& Noronha, 2015; 
Gama, Bezerra, Silva, Vieira e Parente, 2014; Romagnoli et al., 2013; Romagnoli, 2015; Silva et al., 2014). Esses achados, porém, divergem do estudo realizado por Colossi e Falcke (2015), que teve como amostra uma população que se voluntariou para participar da pesquisa, onde a predominância foi de participantes que integram as classes sociais mais abastadas, com grande incidência de pessoas com grau superior de escolarização e renda até $\mathrm{R} \$ 45.000,00$.

Observando as diferenças existentes entre os perfis de casais em situação de violência conjugal que compõem as amostras coletadas em instituições públicas e os que definem a amostra com voluntários, é possível levantar duas hipóteses, que são distintas, mas que estão de certo modo interligadas. A primeira hipótese é de que pela falta de acesso a serviços mais especializados para tratamento dos conflitos conjugais, tais como os acompanhamentos psicoterápicos, ou de saúde em geral, as pessoas de menor poder aquisitivo recorreriam às delegacias em busca de uma ação pontual, que pudesse dar novo direcionamento à relação, um chamado de atenção ao parceiro conjugal para não mais proceder de forma violenta, uma vez que em diversos casos retomam a relação afetiva (Porto \& Brucher-Maluschke, 2014; Romagnoli, 2015).

A outra hipótese e que de certo modo complementa primeira, é de que há uma subnotificação dos eventos de violência conjugal por parte das classes mais abastadas junto às autoridades públicas, gerando assim a falsa impressão de que há uma incidência menor deste fenômeno entre as pessoas de poder aquisitivo mais elevado (Oliveira, 2012). O que levaria a supor que tais resultados divergentes sejam em função dos registros, ou da falta deles, não havendo assim uma relação direta entre ser pobre e se tornar autor de violência conjugal.

No que diz respeito às características biopsicológicas do autor e da vítima, corroboram os resultados desta pesquisa, no que tangem ao uso de álcool, os estudos de Silva, Coelho e Njaine (2014), considerando que os autores de agressão consumiam e tinham acesso a drogas, assim como, em sua grande maioria, havia consumido tal substância no momento em que cometeu o ato agressivo, associado a outros tipos de estímulos, entre eles a "forte emoção" e drogas ilícitas. No tocante ao uso da expressão "forte emoção" descrita nos documentos oficiais das delegacias de polícia, pode estar associada ao disposto no Código Penal, onde a pessoa que comente um delito sob forte emoção pode ter sua penalização diminuída, não sendo solicitado esclarecimento quanto ao tipo de emoção, enquanto expressão do sentimento vivenciado pelo autor da agressão no momento de efetivação do ato agressivo. Neste campo, as informações a respeito da vítima, do estado emocional quando do ocorrido, também são escassas.

A relação conjugal apresenta características que influenciam diretamente na consecução dos atos violentos em seu contexto, neste estudo os resultados apontam como prevalente a agressão física, perpetrada por exparceiro conjugal (Silva et al., 2014; Gama et al., 2014). Demonstram os resultados que as agressões, em sua maioria, foram registradas após o rompimento da relação. Ou seja, a agressão denunciada ocorreu no momento em que a relação já estava rompida, sendo tal situação confirmada pela análise denominada regressão logística que, neste estudo, indicou haver um risco estatístico de ser oito vezes maiores as chances de eventos agressivos ocorrerem com o fim do relacionamento. Associando às ocorrências de eventos anteriores de violência, caberia levantar como hipótese que nas relações rompidas já haviam acontecido eventos de violência, e que isso pode ter levado ao rompimento, porém, frente à continuidade da agressão, supõe-se que a mulher se sentiu encorajada a realizar a denúncia por meio de boletim de ocorrência em delegacias.

Outra possibilidade para ocorrência de eventos de agressão por parte do parceiro após o rompimento da relação pode estar ligada à dificuldade do homem em lidar com a frustração de perder seu objeto de posse, a 
mulher, o que se associa a expressão de ciúmes, que vem do sentimento de propriedade estabelecido pelo patriarcalismo. Oliveira e Bressan (2014), encontraram indícios dessa correlação, no resultado de pesquisa realizada com homens que cumpriam pena pelo assassinato de suas mulheres. Eventos de agressões anteriores também são evidenciados entre os atores deste tipo de violência conjugal, conforme demonstram os resultados de estudo realizado por Gama, Bezerra, Silva, Vieira e Parente (2014). A análise de regressão logística realizada neste estudo, também apontou que há duas vezes mais chances de um homem praticar violência física, se já procedeu desta forma anteriormente.

Quanto às características da violência, neste estudo, prevaleceu a agressão física, praticada no ambiente familiar com destaque para residência do casal e da vítima, no turno da noite, em finais de semana, especialmente no domingo, resultados semelhantes foram encontrados por Romagnoli, Abreu e Silveira (2013); Gama et al. (2014) e Dourado e Noronha (2015). Na agressão física o autor da violência de forma visível, deixa registrada sua marca, seu sinal, impelindo à vítima uma condição de subjugação, medo, o que poderia vincular a agressão física ao emprego concomitante da violência psicológica (Acosta et al., 2015).

Neste estudo, a violência psicológica apresentou um percentual muito elevado de eventos, porém, não foi prevalente na amostra pesquisada, de forma semelhante ao documentado por Gomes, Silveira, Diniz, Paixão, Camargo e Gomes (2013). Esse tipo de violência nem sempre é percebida como violação, já que não deixa marcas no corpo, tal como a agressão física que é melhor identificada pela sociedade em geral. Porém, a violência psicológica tem efeito negativo à mulher violentada, já que pode levá-la ao adoecimento psíquico e físico, sendo por vezes mais lesiva que os demais tipos de agressão, em função de seus resultados à vida das vítimas. Os pesquisadores Gama et al. (2014) encontraram resultados semelhantes, dando conta de que pode haver uma subnotificação desse tipo de violência, considerando que nem sempre a mulher acha que tem direito de denunciar abusos dessa natureza, visto que culturalmente apresenta certa aceitação social, sendo incluída inclusive em repertórios musicais e ditos populares, que de certo modo propagam a violência como evento normal nas relações amorosas.

No tocante aos dados processuais, há um número considerável de homens denunciados que não se reconhecem como autores de agressão. Tal negatória poderia estar ligada, entre outros aspectos, ao sentimento de propriedade que o autor de agressão nutre em relação à vítima; ou a possibilidade de identificar seus atos como responsivos às atitudes da agredida, onde passaria a ser vista como responsável por sofre a agressão, o que levaria o homem a não se ver praticando ato violento, e sim, apenas se defendendo ou ainda, a percepção de que suas ações não se enquadram como violência, por não ser do tipo físico, resultado que também foi verificado por Romagnoli et al. (2013).

Desta forma, a não percepção do homem como autor de agressão pode estar influenciando no fato de não apresentar defesa, frente à citação, e nas ausências injustificadas em audiências processuais (Silva et al, 2015). Os dados demonstram que os réus condenados, em sua maioria, apresentavam comportamento agressivo, característica esta que é levada em consideração para aplicação da penalidade, funcionando como fator agravante para dosar a pena podendo aumentá-la, segundo o Código Penal. Neste estudo, $42 \%$ dos denunciados foram considerados culpados pela agressão à vítima e sentenciados a cumprir pena máxima de um a dois meses, em geral em regime aberto.

É possível perceber que há uma associação de fatores que contribuem para manutenção e crescimento da violência contra a mulher na relação conjugal. Entre os elementos constitutivos de tal fenômeno estão os pertinentes ao perfil do autor, que pode não ter desenvolvido ferramentas positivas para lidar bem com seus sentimentos e frustrações. Há ainda, a possibilidade deste indivíduo, por 
vezes, sentir-se proprietário da sua parceira e, portanto, considerando-se com direito a aplicar penalidades a ela, quando a cônjuge não corresponde aos seus anseios nas diversas esferas da vida.

Neste meandro somam-se fatores contextuais como a cultura local e transmissão do padrão relacional do conflito transmitido de geração em geração, fazendo-o parecer normal, aceitável e propagável aos descendentes, num contínuo que requer um esforço coletivo das instituições e da sociedade em geral para que sejam buscados estratégias e caminhos cada vez mais adequados às transformações necessárias para minimização das diferenças entre gêneros, da quebra de silêncio sobre o tema, dos meios educacionais e de proteção, voltados aos seus atores. Assim, as contribuições das várias áreas de conhecimento, entre elas a Psicologia, em descrever de forma cada vez mais aprofundada este fenômeno e seus partícipes devem ser mais incentivadas a elaborar conhecimentos e seus resultados devem ser empregados para formalização de políticas públicas com maior capacidade de efetividade na sociedade.

Este trabalho pode ser considerado uma iniciativa de contribuir com o aumento da produção referente à violência por parceiro íntimo, que pode auxiliar profissionais que tratam de temáticas semelhantes, uma vez que tratar da violência em questão requer elementos teóricos para compreender os obstáculos existentes no que se refere ao atendimento das pessoas envolvidas em violência conjugal. Destaca-se entre esses obstáculos, a fragmentação dos serviços que compõe a rede de atendimento à mulher em situação de violência, a falta de instituições voltadas ao atendimento dos autores, além da precariedade estrutural dos espaços existentes, seja de acolhimento às vítimas ou reeducação dos agressores. A insuficiência e a falta de investimento na qualificação dos profissionais que atuam nos poucos locais de atendimento disponíveis, se soma às demais dificuldades no enfrentamento desse fenômeno. Esses e outros obstáculos apontam para a necessidade de Políticas Públicas mais eficazes no combate a violência de gênero.
Registra-se por fim, que a Constituição Federal de 1988, estabelece como princípio fundamental da República Federativa do Brasil a dignidade da pessoa humana. Nesse sentido considera-se que essa dignidade somente será alcançada quando homens e mulheres viverem em harmonia compartilhando direitos iguais, respeitando-se uns aos outros como seres semelhantes. Entretanto, o Brasil registra um histórico milenar de discriminação contra a mulher em razão de uma concepção de papéis desempenhados entre o gênero masculino e o feminino, ou seja, ainda vivenciamos uma sociedade marcada pelo patriarcalismo, onde o homem é considerado por parte significativa da sociedade como o centro e a mulher coadjuvante e vítima da segregação econômica, financeira e social.

\section{Considerações finais}

Os resultados obtidos por este estudo descreveram as características biopsicossociais e contextuais dos autores e vítimas de violência por parceiro íntimo, a partir de documentos institucionais vinculados aos órgãos responsáveis pelo acolhimento e proteção das vítimas e da responsabilização do autor. A partir de uma perspectiva sistêmica, entendendo que tais características se influenciam mutuamente para ocorrência das violações que se materializam na convivência afetiva, ou em decorrência desta. Nesse sentido, avalia-se como importante tal tipo de pesquisa, considerando que estas propiciam a consolidação de dados sobre os envolvidos nesse fenômeno. Tais resultados favorecem a visão sobre a demanda que chega até esses órgãos de acolhimento e proteção, que no caso da violência doméstica é um problema mundial em alta escala.

Através desta pesquisa foi possível constatar a falta de informações nos processos consultados, em especial relacionadas às vítimas, para as quais as políticas públicas estariam voltando suas ações, as quais poderiam ser melhores delineadas e aplicadas, se baseadas nas reais necessidades dessas mulheres. Da mesma forma, algumas características pessoais do agressor, também 
são escassas, caso estivessem disponíveis poderiam alcançar o histórico de vida pregressa e de saúde e comportamental dos mesmos, para que se elaborassem programas de atendimento aos mesmos com foco que além da punição, efetivem a função educativa prevista na Lei Maria da Penha.

Aponta-se como limitação desta pesquisa a falta de informações nos processos consultados, em especial relacionadas às vítimas, mas também sobre algumas características pessoais do agressor, que se estivessem disponíveis poderiam alcançar o histórico de vida pregressa e de saúde. Cabe enfatizar que os fatores de risco para vivência de agressão conjugal também não estavam completamente informados nos documentos judiciais no local pesquisado.

Em termos locais, este estudo visou colaborar com a caracterização de homens autores de agressões contra sua parceira amorosa, em especial daqueles que estão inseridos na região amazônica, que apresenta elevado índice de violência contra a mulher, e que necessita de ações contundentes no combate a mesma. Entende-se que a elaboração de políticas públicas voltadas ao enfrentamento da violência se torna mais eficaz se construída a partir de dados, cada vez mais elucidativos, sobre a população que por ela será atendida.

Nesta perspectiva, a participação de profissionais da Psicologia, no atendimento aos homens, mulheres e familiares, envolvidos em contextos conflituosos, de violação de direitos, desde as escutas iniciais, passando pela participação em programas de acompanhamento e no desenvolvimento de pesquisas voltadas ao aprofundamento de conhecimentos pertinentes ao fenômeno da violência na relação de afeto, em muito vem contribuir para qualidade das ações públicas no tratamento adequado dessa demanda, assim como para desvelar cada vez mais os percursos desenvolvimentais dos partícipes e as formas mais propícias de intervenção.

\section{Referências}

Acosta, D. F., Gomes, V. L. O., Fonseca, A. D, \& Gomes, G. C. (2015). Violência contra a Mulher por Parceiro Íntimo: (in) visibilidade do problema. Texto \& Contexto - Enfermagem, 24(1), 121-127. doi:10.1590/0104-07072015001770013.

Akhter, R., \& Wilson, J. K. (2015). Using na Ecological Framework to Understand Men's Reasons for Spousal Abuse: $\mathrm{Na}$ Investigation of the Bangladesh demographic and Health Survey 2007. Journal of Family Violence, 31(1), 27-38. doi: 10.1007/s10896-015-9741-7.

Almeida, A., \& Lourenço, L. M. (2012). Como a violência doméstica/intrafamiliar foi vista ao longo do tempo no Brasil: Breve contextualização. Perspectivas en Psicología, 9(3), 14-23. Recuperado de www.seadpsi.com.ar/revistas/index.php/pe p/article/download/95/41.

Borges, C. C., Magalhães, A. S. \& FéresCarneiro, T. (2014). Liberdade e desejo de constituir família: percepções de jovens adultos. Arquivos Brasileiros de Psicologia, 66(3), 89-103. Recuperado em: http://pepsic.bvsalud.org/scielo.php?script= sci_arttext\&pid=S1809$\underline{52672014000300008 \& \operatorname{lng}=\text { pt\&tlng=pt. }}$

Brasil. Ministério da Saúde. (2001). Violência intrafamiliar: orientações para prática em serviço/ Secretaria de Políticas de Saúde. Brasília: Ministério da Saúde. Recuperado de

http://bvsms.saude.gov.br/bvs/publicacoes/ cd05_19.pdf.

Brasil. Ministério da Saúde [MS]. (2016). População estimada por Região Metropolitana - RIDE segundo Ano-2015. Recuperado de http://tabnet.datasus.gov.br/cgi/tabcgi.exe?i bge/cnv/poptpa.def.

Colossi, P. M. \& Falcke, D. (2013). Gritos do Silêncio: A violência Psicológica no Casal. Psico, 44(3), 10-318. Recuperado de http://revistaseletronicas.pucrs.br/ojs/index. 
php/revistapsico/article/viewFile/11032/10 404.

Colossi, P. M., Razera, J., Haack, K. R., \& Falcke, D. (2015). Violência conjugal: prevalência e fatores associados. Contextos Clínicos, 8(1), 55-66. doi:10.4013/ctc.2015.81.06.

Costa, E. L. F. (2014). O gênero no direito internacional: discriminação, violência e proteção. Belém: Paka-Tatu.

Dourado, S. M., \& Noronha, C. V. (2015). Marcas visíveis e invisíveis: danos ao rosto feminino em episódios de violência conjugal. Ciências e Saúde Coletiva, 20(9). doi: 10.1590/1413-81232015209.19012014.

Gama, I. S, Bezerra, J. G. F, Silva, J. G, Vieira, L. J. E. S., \& Parente, E. O. (2014). Fatores associados à violência física denunciado por mulheres. Journal of Health \& Biological Sciences, 2(4), 168175. doi: $10.12662 / 2317-$ 3076jhbs.v2i4.105.p168-175.2014.

Gracia, E. (2014). Intimate partner violence against women and victim-blaming attitudes among Europeans. World Health Organization (WHO). doi: 10.2471/bblt.13.131391.

Lei $\mathrm{n}^{\circ}$ 11.340, de 07 de agosto de 2006. (2006, 07 agosto). Cria mecanismos para coibir a violência doméstica e familiar contra a mulher, nos termos do $\S 8^{\circ}$ do art. 226 da Constituição Federal, da Convenção sobre a Eliminação de Todas as Formas de Discriminação contra as Mulheres e da Convenção Interamericana para Prevenir, Punir e Erradicar a Violência contra a Mulher; dispõe sobre a criação dos Juizados de Violência Doméstica e Familiar contra a Mulher; altera o Código de Processo Penal, o Código Penal e a Lei de Execução Penal; e dá outras providências. Recuperado de: http://www.planalto.gov.br/ccivil_03/_ato2 004-2006/2006/lei/111340.htm\#art46.

Lopes, B. J., Fonsêca, P. N., Medeiros, E. D., Almeida, A. C., \& Gouveia, V. V. (2016). Escala de Perdão Conjugal (MOFS): evidências de validade de construto no contexto brasileiro. Psico, 47(2), 121-
131. doi: $10.15448 / 1980-$ 8623.2016.2.22439

Marasca, A. R., Colossi, P. M., \& Falcke, D. (2013). Violência Conjugal e Família de Origem: Uma Revisão Sistemática da Literatura de 2006 a 2011. Temas em Psicologia, 21(1), 221-243. doi:10.9788/TP2013.1-16.

Moraes, M. S. B. (2017). Homens Autores de Violência Conjugal: Caracterização Biopsicossocial e a Relação com a Vítima, o Tipo de Agressão Praticada e suas Consequências Processuais (Dissertação de Mestrado). Programa de Pós-Graduação em Teoria e Pesquisa do Comportamento, Universidade Federal do Pará, Belém.

Oliveira, E. R. (2012). Identificando os protagonistas de um problema social: o perfil dos usuários do Juizado

Especializado em violência doméstica e familiar contra a mulher do Estado de São Paulo. Revista Levs, 10, Recuperado em: http://www2.marilia.unesp.br/revistas/index $. \mathrm{php} / \mathrm{levs} / \mathrm{article} / \mathrm{view} / 2639$.

Oliveira, L. R. F., \& Bressan, C. (2014). A percepção do sujeito que matou por amor. Mudanças - Psicologia da Saúde, 22(1), 21-30. doi: $10.15603 / 2176-$ 1019/mud.v22n1p21-30.

Paixão, G. P. N., Gomes, N. P., Diniz, N. M. F., Couto, T. M., Vianna, L. A. C., \& Santos, S. M. P. (2014). Situations which precipitate conflicts in the conjugal relationship: the women's discourse. Texto \& Contexto - Enfermagem, 23(4), 10411049. doi: $10.1590 / 0104-$ 07072014003290013.

Portela, A. P. \& Ratton. J.L. (2015). A teoria social feminista e os homicídios: o desafio de pensar a violência letal contra as mulheres. Contemporânea, 5(1), 93-118. Recuperado de http://www.contemporanea.ufscar.br/conte mporanea/index.php/contemporanea/article/ view/298/130.

Porto, M. \& Brucher-Maluschke, J. S. N. (2014). A permanência de mulheres em situação de violência: consideração de Psicólogas. Psicologia: Teria e Pesquisa, 
30 (3), 267-276. doi: 10.1590/S010237722014000300004 .

Razera, J, Cenci, C. M. B., \& Falcke, D. (2014). Violência Doméstica e Transgeracionalidade: Um Estudo de Caso. IMED, 6(1), 47-51. doi: $10.18256 / 2175-$ 5027/psico-imed.v6n1p47-51.

Rolim, K. I., \& Falcke, D. (2017). Violência Conjugal, Políticas Públicas e Rede de Atendimento: Percepção de Psicólogos(as). Psicologia: Ciência e Profissão,37(4), 939955. doi: 10.1590/1982-3703003332016.

Romagnoli, R. C. (2015). A violência contra a mulher em Montes Claros. BarBarói, 43, 27-47. doi: 10.17058/barbaroi.v0i0.4815.

Romagnoli, R. C., Abreu, L. L. G., \& Silveira, M. F. (2013). A violência contra a mulher em Montes Claros: análise estatística. Gerais: Revista Interinstitucional de Psicologia, 6(2), 282-297. Recuperado de http://pepsic.bvsalud.org/scielo.php?script= sci_arttext\&pid=S1983$82202013000200010 \& \operatorname{lng}=p t \& t \operatorname{lng}=$ pt.

Rosa, M. P. A., \& Freiras, D. (2017). "São milhões de brasileiros que não tem pra onde correr": o "avesso da vida" e a psicologia jurídica no documentário nega. Revista Eletrônica Direito e Conhecimento,1(1), 31-57. Recuperado de http://revistas.cesmac.edu.br/index.php/dec/ article/view/594/493.

Santos, A. S., \& Vieira, F. G. (2015). Honra, desonra e violência contra a mulher
Cachoeirense na década de 1930. Ártemis, XVI (1), 204-215. Recuperado de http://periodicos.ufpb.br/index.php/artemis/ article/viewFile/17358/9872.

Silva, F. A., Silva, F. P. P., Tavares, E. S., Oliveira, H. S. G., Neves, A.L.M., \& Silva, I. R. (2015). Atenção psicossocial a homens autores de violência conjugal contra a mulher: uma construção participativa.

Pesquisas e Práticas Psicossociais, 10(1), 177-191. Recuperado de http://pepsic.bvsalud.org/scielo.php?script= sci arttext\&pid=S180989082015000100015.

Silva, A. C. L. G., Coelho, E. B. S., \& Njaine, K. (2014). Violência conjugal: as controvérsias no relato dos parceiros íntimos em inquéritos policiais. Ciências $e$ Saúde Coletiva, 19(4). doi: 10.1590/1413$\underline{81232014194.01202013 .}$

Stuart, G. L., Moore, T. M., Elkins, S. R., O'Farrell, T. J., Temple, J. R., Ramsey, S. E., \& Shorey, R. C. (2013). The temporal association between substance use and intimate partner violence among women arrested for domestic violence. Journal of Consulting and Clinical Psychology, 81(4), 681-690. doi: 10.1037/a0032876.

Waiselfisz, J. J. (2015). Mapa da Violência 2015: Homicídio de mulheres no Brasil. Brasília: Flacso. Recuperado de http://www.mapadaviolencia.org.br/pdf201 5/MapaViolencia_2015_mulheres.pdf. 


\section{Dados sobre os autores:}

- Maria do Socorro Barros Moraes: Analista Judiciário-Psicóloga e Mediadora de Conflitos do Tribunal de Justiça do Estado do Pará e Psicóloga Clínica. Graduada em Psicologia pela Universidade da Amazônia, Mestre em Teoria e Pesquisa do Comportamento pela UFPA, Pósgraduação lato sensu em Psicopedagogia pela UNINTER e MBA em Desenvolvimento e Gestão de Pessoas pela Fundação Getúlio Vargas (FGV). Instrutora de cursos de Mediação e Conciliação de Judicial, Gestão de Conflitos, Relações Interpessoais, Desenvolvimento de Equipes e Liderança.

- Lília Ieda Chaves Cavalcante: professora da Faculdade de Serviço Social da UFPA. Está credenciada como professor orientador ao Programa de Pós-Graduação em Teoria e Pesquisa do Comportamento, área de concentração da Ecoetologia. É Mestre em Serviço Social e Doutora pelo Programa de Pós-Graduação em Teoria e Pesquisa do Comportamento da UFPA, com Pósdoutorado pelo Programa de Pós-Graduação em Psicologia da UFRGS. Tem experiência de trabalho na área de Serviço Social e Psicologia, com ênfase na Psicologia do Desenvolvimento Humano. Bolsista de Produtividade em Pesquisa do CNPq - Nível 2 - CAPS - Psicologia e Serviço Social.

- Zenildo Costa Pantoja: Graduado no curso de Serviço Social pela Universidade Federal do Pará. Vinculado ao Programa de Pós-graduação em Teoria e Pesquisa do Comportamento, desenvolvendo pesquisa sobre a história de vida e os contextos de desenvolvimento de autores de violência sexual contra crianças e adolescentes. Atuou como estagiário em 2015 no Tribunal de Justiça na $1^{\text {a }}$ Vara da Infância e Juventude. Tem experiência na área de violência contra a mulher, na política de acolhimento à mulher em situação de violência.

- Lucilene Paiva Costa: Graduada pela UFPA em Psicologia (2012) e Licenciatura Plena em Pedagogia (1999). Possui Mestrado pela UFPA em Teoria e Pesquisa do Comportamento (2015). Atualmente é analista na Defensoria Pública do Estado do Pará na área da Pedagogia. É membro do Grupo de Estudos de Autores de Violência (GEAV), o qual pertence ao Laboratório de Ecologia do Desenvolvimento (LED) do Programa de Pós-Graduação em Teoria e Pesquisa do Comportamento da UFPA, também é membro do Grupo de Estudos e Pesquisas Pedagogia em Movimento (GEPPEM) da Universidade do Estado do Pará. 